\title{
Lanthanide compounds containing a benzo-15-crown-5 derivatised [60]fullerene and the related $\left[\mathrm{Tb}\left(\mathrm{H}_{2} \mathrm{O}\right)_{3}\left(\mathrm{NO}_{3}\right)_{2}(\right.$ acac $\left.)\right] \cdot \mathrm{C}_{14} \mathrm{H}_{20} \mathrm{O}_{5}$ supramolecular adduct $\dagger$
}

\author{
Paula C. R. Soares-Santos, ${ }^{a}$ Tito Trindade, ${ }^{a}$ Augusto C. Tomé,${ }^{a}$ João Rocha, ${ }^{a}$ \\ Rute A. Sá Ferreira, ${ }^{b}$ Luís D. Carlos, ${ }^{b}$ Filipe A. Almeida Paz, ${ }^{a c}$ Jacek Klinowski $^{c}$ and \\ Helena I. S. Nogueira*a \\ ${ }^{a}$ Department of Chemistry, University of Aveiro, 3810-193 Aveiro, Portugal. \\ E-mail:helena@dq.ua.pt \\ ${ }^{\boldsymbol{b}}$ Department of Physics, CICECO, University of Aveiro, 3810-193 Aveiro, Portugal \\ ${ }^{c}$ Department of Chemistry, University of Cambridge, Lensfield Road, Cambridge. \\ $U K C B 21 E W$
}

Received (in Durham, UK) 2nd July 2004, Accepted 15th September 2004

First published as an Advance Article on the web 18th October 2004

\begin{abstract}
Novel lanthanum(III), europium(III) and terbium(III) compounds of a benzo-15-crown-5 [60]fulleropyrrolidine were isolated in the solid state and characterised using vibrational (infrared and Raman) spectroscopy and by ${ }^{13} \mathrm{C}$ CP MAS NMR for the lanthanum(III) compound. The photoluminescence properties were investigated for the europium(III) and terbium(III) compounds. The related $\left[\mathrm{Tb}\left(\mathrm{H}_{2} \mathrm{O}\right)_{3}\left(\mathrm{NO}_{3}\right)_{2}(\mathrm{acac})\right]$. $\mathrm{C}_{14} \mathrm{H}_{20} \mathrm{O}_{5}$ [where acac ${ }^{-}=$acetylacetonate and $\mathrm{C}_{14} \mathrm{H}_{20} \mathrm{O}_{5}=$ benzo-15-crown-5] supramolecular adduct was isolated using similar synthetic conditions, in the absence of [60]fullerene, and its crystal structure used as a model for the coordination sphere of the lanthanide [60]fullerene derivatives, with further supporting evidence given by photoluminescence measurements.
\end{abstract}

\section{Introduction}

The coordination chemistry of lanthanide cations with derivatised [60]fullerene ligands is a promising research field yet to be explored. Although the reactions of transition metal complexes with fullerene derivatives have been reported for an interesting array of compounds, ${ }^{1}$ and it is known that the majority of lanthanide metals can be trapped inside the higher fullerenes, such as $\mathrm{C}_{82}$, to form relatively stable endohedral metallofullerenes, ${ }^{2}$ novel isolated exohedral fullerene compounds involving lanthanides are largely unknown. A study in solution was reported by Garlaschelli et al. ${ }^{3}$ on the formation of [60]fullerene ylidene malonate supramolecular triads containing europium followed by $\mathrm{UV} / \mathrm{V}$ is absorption.

We have been interested in the photoluminescence behaviour of lanthanide complexes containing aromatic $\mathrm{N}$ and $\mathrm{O}$ donor ligands such as 3-hydroxypicolinic acid, ${ }^{4}$ 2-hydroxynicotinic acid, ${ }^{5}$ picolinic acid ${ }^{6}$ and 2,6-dihydroxybenzoic acid. ${ }^{7}$ One of our aims in studying the coordination chemistry of lanthanides with derivatised [60]fullerene ligands was to investigate the effect of the [60]fullerene units on the photoluminescence properties of the exohedral fullerene lanthanide compounds, as monofunctionalised [60]fullerene compounds are known to be photoactive and electroactive. ${ }^{8-10}$ In a preliminary report, we described the synthesis and characterisation of a europium(III) compound containing a salicylato derivatised [60]fullerene. ${ }^{11}$ Herein we describe the synthesis of novel lanthanide(III) compounds containing a benzo-15-crown-5 derivatised [60]fullerene unit. These are examples of [60]fullerene compounds containing an external lanthanide(III) cation, which have been for the first time isolated in the solid state. The [60]fullerene derivative used in the reaction with the

$\dagger$ Where acac $^{-}$is acetylacetonate, and $\mathrm{C}_{14} \mathrm{H}_{20} \mathrm{O}_{5}$ is benzo-15-crown-5. lanthanide cations was the benzo-15-crown-5 [60]fulleropyrrolidine (1) prepared by adaptation of the methods described by Maggini et al. ${ }^{12}$ and Guo et al. ${ }^{13}$ Lanthanide complexes of macrocyclic ligands have been widely studied, ${ }^{14-16}$ including those with crown ether compounds. ${ }^{17,18}$ In the case of the latter, lanthanide ions are expected to be easily accommodated in the size-fitted cavity of crown-5. ${ }^{19,20}$ Compound 1 was prepared in order to have a crown- 5 moiety covalently bonded to [60]fullerene and freely available for lanthanide coordination. Solid compounds $\mathbf{2 - 4}$ were obtained by reaction of the benzo-15-crown-5 [60]fulleropyrrolidine (1) with lanthanu$\mathrm{m}$ (III), europium(III) and terbium(III) cations, respectively, and characterised by infrared and Raman spectroscopy and by ${ }^{13} \mathrm{C}$ CP MAS NMR for the lanthanum(III) compound (2). The luminescence properties were investigated for the europium(III) (3) and terbium(III) (4) compounds. In order to understand the possible coordination sphere of the lanthanide [60]fullerene derivatives 2-4 (and due to the difficulty in crystallising [60]fullerene based compounds), the same synthetic procedure was used as in the preparation of related compounds by replacing 1 for benzo-15-crown-5. The supramolecular adduct $\left[\mathrm{Tb}\left(\mathrm{H}_{2} \mathrm{O}\right)_{3}\left(\mathrm{NO}_{3}\right)_{2}(\mathrm{acac})\right] \cdot \mathrm{C}_{14} \mathrm{H}_{20} \mathrm{O}_{5} 5$ [where acac ${ }^{-}=$acetylacetonate and $\mathrm{C}_{14} \mathrm{H}_{20} \mathrm{O}_{5}=$ benzo-15-crown-5] was isolated and its crystal structure solved using single-crystal X-ray diffraction.

\section{Results and discussion}

\section{Benzo-15-crown-5 [60]fulleropyrrolidine 1 and its lanthanide compounds 2,3 and 4}

The benzo-15-crown-5 [60]fulleropyrrolidine 1 was obtained from the 1,3-dipolar cycloaddition of $\mathrm{C}_{60}$ with the azomethine ylide generated in situ from the reaction of 4-formyl-benzo15-crown-5 and $N$-methylglycine, as shown in Scheme 1. The 


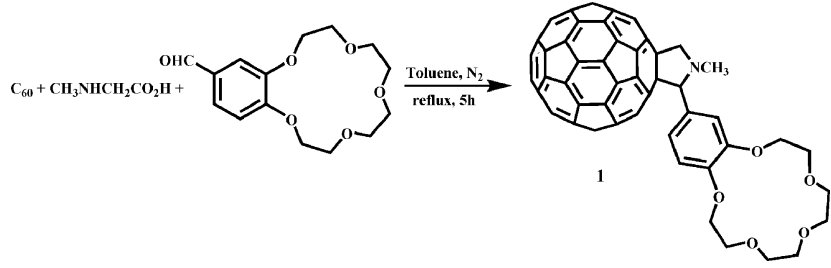

Scheme 1

pure product was characterised by mass spectrometry, ${ }^{1} \mathrm{H}$ and ${ }^{13} \mathrm{C}$ NMR, FT-IR and FT-Raman spectroscopy (see Experimental Section).

The reaction of compound $\mathbf{1}$ with the lanthanide(III) acetylacetonates in chloroform, followed by addition of the respective lanthanide(III) nitrates, originated products $\mathbf{2 - 4}$, containing lanthanum(III), europium(III) and terbium(III), respectively. The isolated compounds were found to be highly insoluble in all the common solvents, thus preventing further structural characterisation from solution.

Relevant infrared and Raman spectroscopic data for the solid compounds are shown in Table 1; tentative assignments are based on those found in the literature for benzo-15-crown$5^{21,22}$ and europium acetylacetonato complexes. ${ }^{23}$ The spectra of compounds 2-4 show clear evidence of the presence of benzo-15-crown-5 [60]fulleropyrrolidine 1 . The presence of the $\mathrm{C}_{60}$ moiety in compounds $\mathbf{1 - 4}$ is shown both in the infrared and Raman spectra by a set of $\mathrm{C}_{60}$ characteristic bands summarised in Table 1. In particular, the very strong band at $526 \mathrm{~cm}^{-1}$ in the infrared spectrum of both $\mathrm{C}_{60}$ and $\mathbf{1}$ is clearly seen in the spectra of compounds 2-4. The Raman spectra show a clearer set of $\mathrm{C}_{60}$ bands, in particular a very strong band at $1468 \mathrm{~cm}^{-1}$ for pure $\mathrm{C}_{60}$ and at $1462 \mathrm{~cm}^{-1}$ for compound 1 , together with a strong band at $1574 \mathrm{~cm}^{-1}$ for $\mathrm{C}_{60}$ and $1571 \mathrm{~cm}^{-1}$ for $\mathbf{1}$, that are both clearly shown in the Raman spectra of compounds 2-4 (at 1461/1568, 1462/1569 and $1467 / 1575 \mathrm{~cm}^{-1}$, respectively). Characteristic bands of the benzo-15-crown-5 moieties ${ }^{21,22}$ are observed in the infrared spectra of compounds 1-4. Very strong bands assigned to the $\mathrm{C}-\mathrm{O}-\mathrm{C}$ stretches are observed at $1124 \mathrm{~cm}^{-1}$ for $\nu(\mathrm{C}-\mathrm{O}-\mathrm{C})$ and at 1259 and $1228 \mathrm{~cm}^{-1}$ for $\nu(\mathrm{Ar}-\mathrm{O}-\mathrm{C})(\mathrm{Ar}=$ aromatic carbon atom) in the benzo-15-crown-5 spectrum and are clearly shown in the infrared spectrum of $\mathbf{1}$ with very small shifts (up to $8 \mathrm{~cm}^{-1}$ ). These bands are observed in the infrared spectra of compounds 2-4, showing weak or medium intensity. Diagnostic bands characteristic of acetylacetonato $\left(\mathrm{acac}^{-}\right)$moieties are observed in the infrared spectra of compounds $\mathbf{2 - 4}$, in particular the $\mathrm{C}-\mathrm{CH}_{3}$ and $\mathrm{C}-\mathrm{O}$ combined stretching modes ${ }^{23}$ around $1020 \mathrm{~cm}^{-1}$. The presence of $\mathrm{acac}^{-}$was also detected by ${ }^{13} \mathrm{C}$ solid-state NMR in the $\mathrm{La}^{3+}$ compound 2 , as shown below.

The supramolecular adduct $\left[\mathrm{Tb}\left(\mathrm{H}_{2} \mathrm{O}\right)_{3}\left(\mathrm{NO}_{3}\right)_{2}\right.$ (acac) $]$. $\mathrm{C}_{14} \mathrm{H}_{20} \mathrm{O}_{5} \mathbf{5}$ was obtained using the same synthetic approach that was used for the preparation of compounds 2-4 by replacing compound 1 by benzo-15-crown-5 (excluding the $\mathrm{C}_{60}$ moiety). The X-ray crystal structure of compound $\mathbf{5}$ was solved (see below) and was used as a model for a possible coordination sphere of the lanthanide [60]fullerene derivatives 2-4, according to the infrared, Raman and NMR data and further supported by the photoluminescence results. The presence of the benzo-15-crown-5 moiety together with the acetylacetonate ligand in compound $\mathbf{5}$ was detected in the infrared and Raman spectra (Table 1), as described for compounds 2-4. A diagnostic band characteristic of the coordinated bidentate nitrate ligand, ${ }^{22} \nu_{\mathrm{s}}\left(\mathrm{NO}_{2}\right)$, is observed in the infrared and Raman spectra of compound 5, at $1049 \mathrm{~cm}^{-1}$, and is also shown in the spectra of compounds $\mathbf{2 - 4}$, around $1045 \mathrm{~cm}^{-1}$. The inclusion of the lanthanides in compounds 2-4 was further confirmed by EDX measurements.

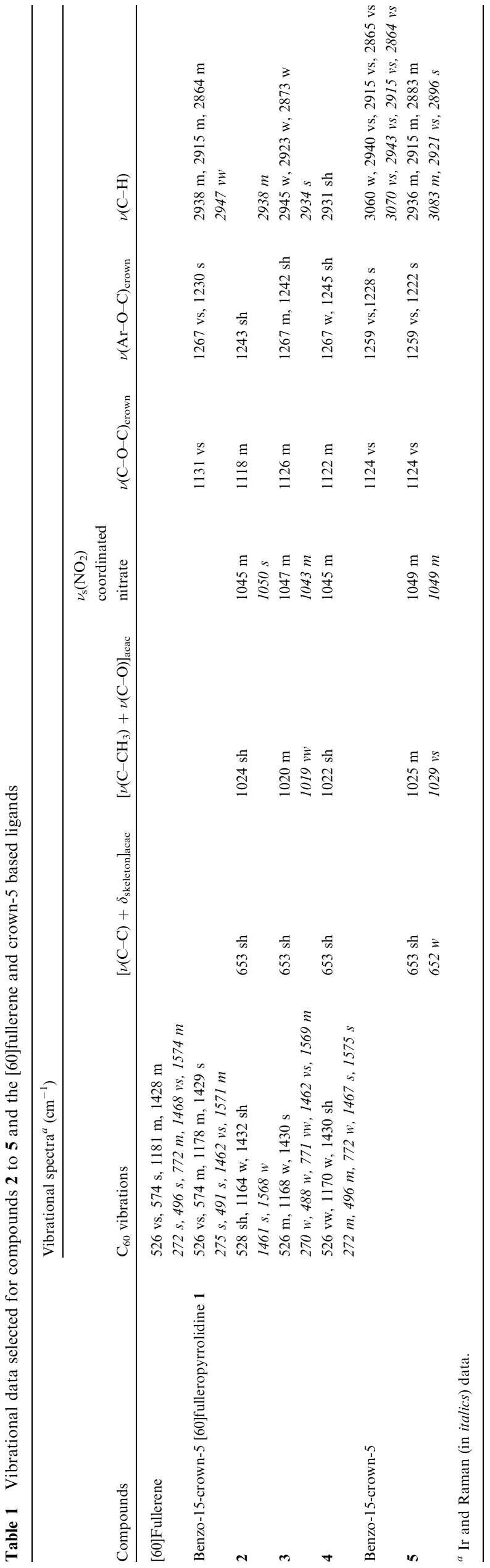

New J. Chem., 2004,28,1352-1358 


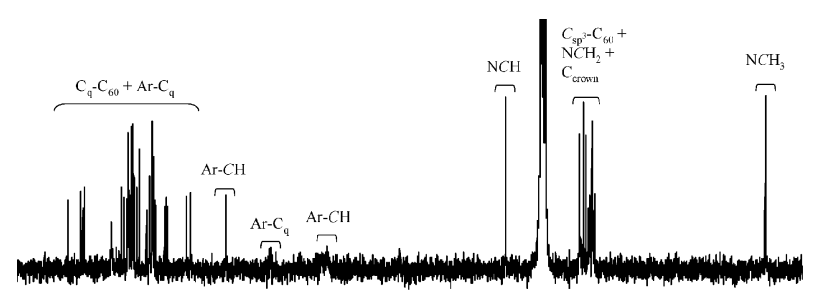

$\begin{array}{lllllllllllll}160 & 150 & 140 & 130 & 120 & 110 & 100 & 90 & 80 & 70 & 60 & 50 & 40\end{array}$

Fig. $1{ }^{13} \mathrm{C}$ NMR spectrum of 1 in $\mathrm{CDCl}_{3}$ solution.

The ${ }^{13} \mathrm{C}$ NMR spectrum of the benzo-15-crown-5 [60]fulleropyrrolidine 1 is presented in Fig. 1 along with the respective assignments based in the literature describing analogous compounds. $^{24,25}$ Due to the low solubility of compounds $2-\mathbf{4}$ in common solvents, the ${ }^{13} \mathrm{C}$ CP MAS NMR spectrum was recorded for the lanthanum(III) compound $\mathbf{2}$ and is shown in Fig. 2 together with the spectrum of compound $\mathbf{1}$.

The ${ }^{13} \mathrm{C}$ CP MAS NMR spectrum of the lanthanum(III) compound 2 shows signals assigned to the acetylacetonate ligand, together with the signals for the $\mathrm{C}_{60}$ and benzo-15crown-5 moieties. The signals for the $\mathrm{C}_{60}$ are of low intensity but in the same position as those of compound 1 (see Fig. 2). The spectrum of compound $\mathbf{2}$ confirms the presence in the solid compound of the acetylacetonate ligand and of the derivatised fullerene 1. In this way, NMR data also supports that compound $\mathbf{5}$ can be suggested as a possible model for the coordination sphere of compounds $\mathbf{2 - 4}$, for which a possible formula would be $\left[\mathrm{Ln}\left(\mathrm{H}_{2} \mathrm{O}\right)_{3}\left(\mathrm{NO}_{3}\right)_{2}(\mathrm{acac})\right] \cdot \mathrm{C}_{77} \mathrm{H}_{25} \mathrm{NO}_{5} \quad$ [where $\mathrm{Ln}=\mathrm{La} \mathrm{2}$, Eu 3 and $\mathrm{Tb} 4$; $\mathrm{acac}^{-}=$acetylacetonate and $\mathrm{C}_{77} \mathrm{H}_{25} \mathrm{NO}_{5}=$ benzo-15-crown-5 [60]fulleropyrrolidine].

\section{Crystal structure of $\left[\mathrm{Tb}\left(\mathrm{H}_{2} \mathrm{O}\right)_{3}\left(\mathrm{NO}_{3}\right)_{2}(\mathrm{acac})\right] \cdot \mathrm{C}_{14} \mathrm{H}_{20} \mathrm{O}_{5}(5)$ supramolecular adduct}

$\left[\mathrm{Tb}\left(\mathrm{H}_{2} \mathrm{O}\right)_{3}\left(\mathrm{NO}_{3}\right)_{2}(\mathrm{acac})\right] \cdot \mathrm{C}_{14} \mathrm{H}_{20} \mathrm{O}_{5}(\mathbf{5})$ was synthesised using a similar procedure to that employed for compounds 2-4 but in the absence of the $\mathrm{C}_{60}$ moiety (see Experimental Section). Single-crystals were manually harvested and characterised structurally using single-crystal X-ray diffraction. $\ddagger$

The structure contains one crystallographically unique, ninecoordinated $\left\{\mathrm{TbO}_{9}\right\}, \mathrm{Tb}^{3+}$ site exhibiting a highly distorted pentagonal bipyramidal coordination environment composed of one acetylacetonate, three water molecules and two nitrate anions (Table 2), which leads to the formation of a discrete and neutral complex with empirical formula of $\left[\mathrm{Tb}\left(\mathrm{H}_{2} \mathrm{O}\right)_{3}\right.$ $\left(\mathrm{NO}_{3}\right)_{2}$ (acac)] (Fig. 3). This complex is closely related with those recently reported by Fukuda et al. for a series of lanthanide cations and containing 2,2:6,2-terpyridine (terpy). ${ }^{26}$

The nitrate anions are occupying axial positions of the pentagonal bipyramid, acting as bidentate chelating ligands with an average $\mathrm{Tb}-\mathrm{O}$ distance of $c a .2 .48 \AA$ (Table 2 ) and bite angle of $51.5^{\circ}$. The acetylacetonate ligand adopts its typical coordination fashion as described in the literature for related complexes with lanthanides, ${ }^{26-33}$ with the formation of a sixmembered chelate ring having a bite angle of $74.72(10)^{\circ}$, very similar to those observed in the lanthanide series reported by Fukuda et al. ${ }^{26}$ The three bond lengths with water molecules are statistically identical with the average $\mathrm{Tb}-\mathrm{O}_{\text {water }}$ distance being $c a .2 .42 \AA$ (Table 2) and consistent with the values

$\ddagger$ Crystal data: $\mathrm{C}_{19} \mathrm{H}_{33} \mathrm{~N}_{2} \mathrm{O}_{16} \mathrm{~Tb}, M=704.39$, orthorhombic, space group Pbca, $T=180(2) \mathrm{K}, Z=8, a=15.912(3), b=15.912(3), c=$ $18.556(4) \AA, V=5321.2(18) \AA^{3}, \mu(\mathrm{Mo}-\mathrm{K} \alpha)=2.736 \mathrm{~mm}^{-1}, D_{\mathrm{c}}=1.759$ $\mathrm{g} \mathrm{cm}^{-3}$. Of a total of 48500 reflections collected, 6091 were independent $\left(R_{\text {int }}=0.0779\right)$. Final $R 1=0.0357[I>2 \sigma(I)]$ and $w R 2=0.0734$ (all data). Data completeness to theta $=27.48^{\circ}, 99.7 \%$. CCDC 240925 . See http://www.rsc.org/suppdata/nj/b4/b410068a/ for crystallographic data in .cif or other electronic format.

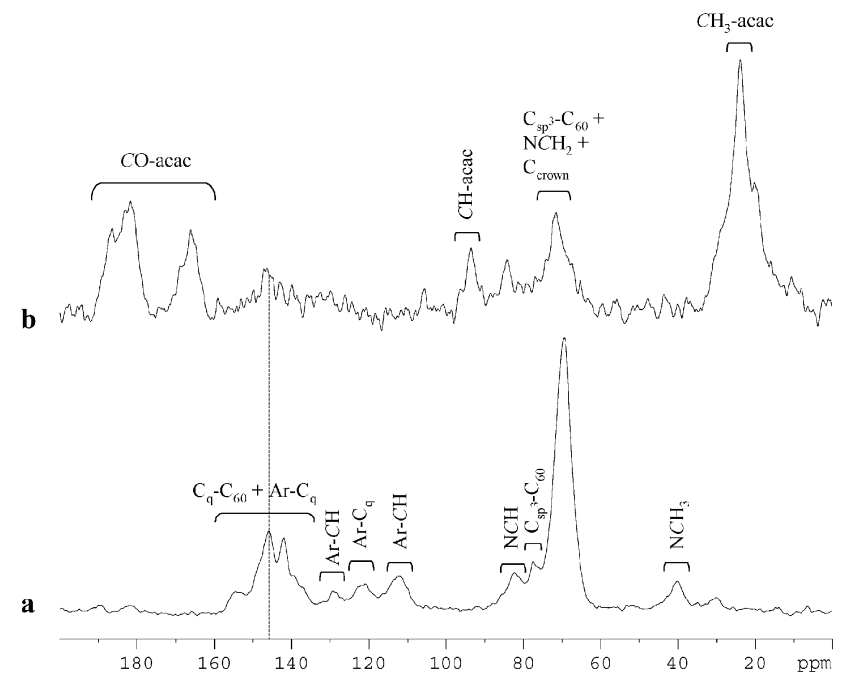

Fig. $2{ }^{13} \mathrm{C}$ CP MAS NMR spectrum of $\mathbf{1}$ (a) and its La(III) compound 2 (b).

reported for related structures. ${ }^{5,7,34-37}$ These coordinated water molecules are further involved in five strong homonuclear $\mathrm{O}$ $\mathrm{H}$... O hydrogen bonds (Table 3) with two neighbouring benzo-15-crown-5 molecules, leading to the formation of a zigzag supramolecular one-dimensional tape (Fig. 4) in which the $\mathrm{Tb}(1) \cdots \mathrm{Tb}(1)^{\mathrm{i}}$ distance is $8.8236(15) \AA$ (symmetry code used to generate equivalent atoms: (i) $-x, 1 / 2+y, 1 / 2-z$ ).

\section{Luminescence}

Fig. 5a shows the room-temperature (RT) excitation (PLE) spectrum of compound $\left[\mathrm{Tb}\left(\mathrm{H}_{2} \mathrm{O}\right)_{3}\left(\mathrm{NO}_{3}\right)_{2}(\mathrm{acac})\right] \cdot \mathrm{C}_{14} \mathrm{H}_{20} \mathrm{O}_{5} 5$ monitored around the more intense emission line of the cation. The spectrum exhibits a series of straight lines assigned to the $\mathrm{Tb}^{3+}$ intra- $4 \mathrm{f}^{8}$ transitions $\left({ }^{7} \mathrm{~F}_{6} \rightarrow{ }^{5} \mathrm{G}_{4,5},{ }^{5} \mathrm{D}_{2-4}\right)$ that superimpose a large broad band in the ultraviolet-blue spectral region $(250-400 \mathrm{~nm})$. This band is mainly formed by two components peaking around 287 and $316 \mathrm{~nm}$ and might arise from the ligands excited levels, as will be discussed below.

Fig. 6 displays the RT emission (PL) spectra of the Tb-based compound $\mathbf{5}$ excited within the large broad band $(287 \mathrm{~nm})$ and directly into the intra- $4 \mathrm{f}^{8}$ levels of the metal ion $(345 \mathrm{~nm})$. Both spectra exhibit a series of straight lines assigned to the ${ }^{5} \mathrm{D}_{4} \rightarrow$

Table 2 Bond lengths (in $\AA$ ) and angles (in ${ }^{\circ}$ ) for the $\left[\mathrm{Tb}\left(\mathrm{H}_{2} \mathrm{O}\right)_{3}\right.$ $\left(\mathrm{NO}_{3}\right)_{2}$ (acac)] complex

\begin{tabular}{llll}
\hline $\mathrm{Tb}(1)-\mathrm{O}(1 \mathrm{~W})$ & $2.436(3)$ & $\mathrm{Tb}(1)-\mathrm{O}(3)$ & $2.484(3)$ \\
$\mathrm{Tb}(1)-\mathrm{O}(2 \mathrm{~W})$ & $2.437(3)$ & $\mathrm{Tb}(1)-\mathrm{O}(4)$ & $2.495(3)$ \\
$\mathrm{Tb}(1)-\mathrm{O}(3 \mathrm{~W})$ & $2.388(3)$ & $\mathrm{Tb}(1)-\mathrm{O}(6)$ & $2.504(3)$ \\
$\mathrm{Tb}(1)-\mathrm{O}(1)$ & $2.320(3)$ & $\mathrm{Tb}(1)-\mathrm{O}(7)$ & $2.431(3)$
\end{tabular}

$\mathrm{Tb}(1)-\mathrm{O}(2)$

$2.303(3)$

$\mathrm{O}(1 \mathrm{~W})-\mathrm{Tb}(1)-\mathrm{O}(2 \mathrm{~W})$

$\mathrm{O}(1 \mathrm{~W})-\mathrm{Tb}(1)-\mathrm{O}(3)$

68.83(11) $\mathrm{O}(1)-\mathrm{Tb}(1)-\mathrm{O}(3)$

$\mathrm{O}(1 \mathrm{~W})-\mathrm{Tb}(1)-\mathrm{O}(4)$

104.06(10) $\mathrm{O}(1)-\mathrm{Tb}(1)-\mathrm{O}(4)$

$74.74(10) \quad \mathrm{O}(1)-\mathrm{Tb}(1)-\mathrm{O}(6)$

$77.78(10)$

$\mathrm{O}(1 \mathrm{~W})-\mathrm{Tb}(1)-\mathrm{O}(6)$

$\mathrm{O}(2 \mathrm{~W})-\mathrm{Tb}(1)-\mathrm{O}(3)$

117.74(11) $\quad \mathrm{O}(1)-\mathrm{Tb}(1)-\mathrm{O}(7)$

$105.40(10)$

$118.23(10)$

$\mathrm{O}(2 \mathrm{~W})-\mathrm{Tb}(1)-\mathrm{O}(4)$

125.62(10) $\mathrm{O}(2)-\mathrm{Tb}(1)-\mathrm{O}(1 \mathrm{~W})$

$143.77(10)$

$\mathrm{O}(2 \mathrm{~W})-\mathrm{Tb}(1)-\mathrm{O}(6)$

$76.15(11) \quad \mathrm{O}(2)-\mathrm{Tb}(1)-\mathrm{O}(2 \mathrm{~W})$

$142.80(10)$

$\mathrm{O}(3 \mathrm{~W})-\mathrm{Tb}(1)-\mathrm{O}(1 \mathrm{~W})$

$\mathrm{O}(3 \mathrm{~W})-\mathrm{Tb}(1)-\mathrm{O}(2 \mathrm{~W})$

71.49(10) $\mathrm{O}(2)-\mathrm{Tb}(1)-\mathrm{O}(3 \mathrm{~W})$

$80.75(9)$

$\mathrm{O}(3 \mathrm{~W})-\mathrm{Tb}(1)-\mathrm{O}(3)$

135.01(10) $\mathrm{O}(2)-\mathrm{Tb}(1)-\mathrm{O}(1)$

$74.72(10)$

73.37(9) $\mathrm{O}(2)-\mathrm{Tb}(1)-\mathrm{O}(3) \quad 73.04(10)$

$78.98(10) \quad \mathrm{O}(2)-\mathrm{Tb}(1)-\mathrm{O}(4) \quad 121.39(10)$

$\mathrm{O}(3 \mathrm{~W})-\mathrm{Tb}(1)-\mathrm{O}(4)$

73.28(9) $\quad \mathrm{O}(2)-\mathrm{Tb}(1)-\mathrm{O}(6)$

$74.80(10)$

$\mathrm{O}(3 \mathrm{~W})-\mathrm{Tb}(1)-\mathrm{O}(6)$

69.93(10) $\mathrm{O}(2)-\mathrm{Tb}(1)-\mathrm{O}(7)$

90.76(11)

$\mathrm{O}(3 \mathrm{~W})-\mathrm{Tb}(1)-\mathrm{O}(7)$

$\mathrm{O}(1)-\mathrm{Tb}(1)-\mathrm{O}(1 \mathrm{~W})$

$121.10(10) \quad \mathrm{O}(7)-\mathrm{Tb}(1)-\mathrm{O}(1 \mathrm{~W})$

$75.80(10)$

$\mathrm{O}(1)-\mathrm{Tb}(1)-\mathrm{O}(2 \mathrm{~W})$

$\mathrm{O}(1)-\mathrm{Tb}(1)-\mathrm{O}(3 \mathrm{~W})$

$80.61(11)$

$\begin{array}{lll}136.12(9) & \mathrm{O}(7)-\mathrm{Tb}(1)-\mathrm{O}(3) & 152.46(11)\end{array}$

150.14(10) 


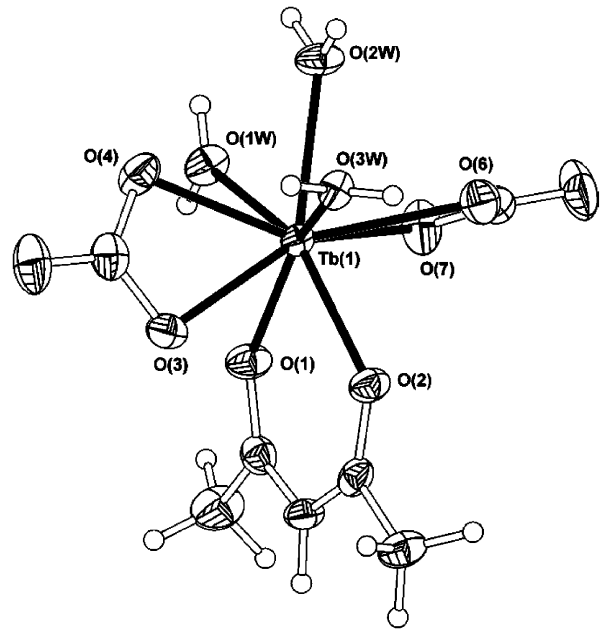

Fig. 3 Schematic representation of the distorted pentagonal bipyramidal coordination environment of the crystallographic unique $\mathrm{Tb}^{3+}$ metal centre in $\left[\mathrm{Tb}\left(\mathrm{H}_{2} \mathrm{O}\right)_{3}\left(\mathrm{NO}_{3}\right)_{2}(\mathrm{acac})\right] \cdot \mathrm{C}_{14} \mathrm{H}_{20} \mathrm{O}_{5}$. Thermal ellipsoids are drawn at the $50 \%$ probability level and selected labels are given for the atoms belonging to the first coordination sphere of $\mathrm{Tb}(1)$. For bond lengths (in $\AA$ ) and angles (in ${ }^{\circ}$ ) see Table 2.

${ }^{7} \mathrm{~F}_{6-2}$ intra- $4 \mathrm{f}^{8}$ transitions and a low-intensity broad band between $380-500 \mathrm{~nm}$. This band may be ascribed to a transition occurring within the ligands levels. No significant changes could be detected in the Tb-related emission lines, namely in the number of Stark components, energy and full width at half maximum (fwhm), thus strongly suggesting the existence of only one average local site for the metal cations.

${ }^{5} \mathrm{D}_{4}$ lifetime was monitored within the more intense line of the ${ }^{5} \mathrm{D}_{4} \rightarrow{ }^{7} \mathrm{~F}_{5}$ transition using a $345 \mathrm{~nm}$ excitation wavelength (not shown). Measured data can be described by a single exponential function, revealing a lifetime of $\tau=0.745 \pm$ $0.012 \mathrm{~ms}$. This reinforces the previous suggestion that all the $\mathrm{Tb}^{3+}$ metal ions lie in the same average local environment.

The PL features of the $\mathrm{Eu}^{3+}$ and $\mathrm{Tb}^{3+}$ compounds of a benzo-15-crown-5 [60]fulleropyrrolidine were investigated by photoluminescence spectroscopy. Only the $\mathrm{Eu}^{3+}$-based [60]fullerene derivative compound 3 showed efficient PL between $12 \mathrm{~K}$ and $\mathrm{RT}$. In fact, for the $\mathrm{Tb}^{3+}$-based [60]fullerene derivative compound $\mathbf{4}$ no emission was detected within the temperature range $12-300 \mathrm{~K}$. The PLE spectrum of compound 3 monitored around the $\mathrm{Eu}^{3+}$ more intense line is plotted in Fig. 5b. The spectrum shows a series of straight lines ascribed to the intra- $4 \mathrm{f}^{6}{ }^{7} \mathrm{~F}_{0,1} \rightarrow{ }^{5} \mathrm{D}_{4,2,1},{ }^{5} \mathrm{G}_{\mathrm{J}},{ }^{5} \mathrm{~L}_{6}$ and two vibronic Stokes-lines (marked with an asterisk in Fig. 5) in the sideband of the ${ }^{7} \mathrm{~F}_{0} \rightarrow{ }^{5} \mathrm{D}_{2}$ and ${ }^{7} \mathrm{~F}_{0} \rightarrow{ }^{5} \mathrm{D}_{0}$ (not shown in Fig. 5) transitions. These satellite lines also appear in the PLE spectrum obtained at $12 \mathrm{~K}$ (inset of Fig. 5). Their vibration frequency occurs around $650 \mathrm{~cm}^{-1}$ and accordingly to infrared and Raman results they might be assigned to the $\mathrm{C}-\mathrm{C}$ stretches and deformation vibrations of coordinated acac ligand, ${ }^{23} \nu(\mathrm{C}-$ C) $+\delta_{\text {skeleton, }}$ (see Table 1 ). The intra- $4 \mathrm{f}^{6}$ lines overlap a large broad band occurring in the same spectral region as that

Table 3 Distances (in $\AA$ ) and angles (in ${ }^{\circ}$ ) between Donors (D) and Acceptors (A) of the D-H...A hydrogen bonds ${ }^{a}$

\begin{tabular}{lll}
\hline $\mathrm{D} \cdots \mathrm{A}$ & $d(\mathrm{D} \cdots \mathrm{A})$ & $<(\mathrm{D}-\mathrm{H} \cdots \mathrm{A})$ \\
\hline $\mathrm{O}(1 \mathrm{~W})-\mathrm{H}(1 \mathrm{D}) \cdots \mathrm{O}(12)$ & $3.047(5)$ & $152(4)$ \\
$\mathrm{O}(1 \mathrm{~W})-\mathrm{H}(1 \mathrm{E}) \cdots \mathrm{O}(9)$ & $2.968(4)$ & $120(4)$ \\
$\mathrm{O}(2 \mathrm{~W})-\mathrm{H}(2 \mathrm{~A}) \cdots \mathrm{O}(12)$ & $2.749(4)$ & $172(4)$ \\
$\mathrm{O}(3 \mathrm{~W})-\mathrm{H}(3 \mathrm{~A}) \cdots \mathrm{O}(13)^{\mathrm{i}}$ & $2.790(4)$ & $170(4)$ \\
$\mathrm{O}(3 \mathrm{~W})-\mathrm{H}(3 \mathrm{~B}) \cdots \mathrm{O}(11)^{\mathrm{i}}$ & $2.771(4)$ & $173(4)$
\end{tabular}

${ }^{a}$ Symmetry codes used to generate equivalent atoms: (i) $-x,-1 / 2+y$, $1 / 2-z$.

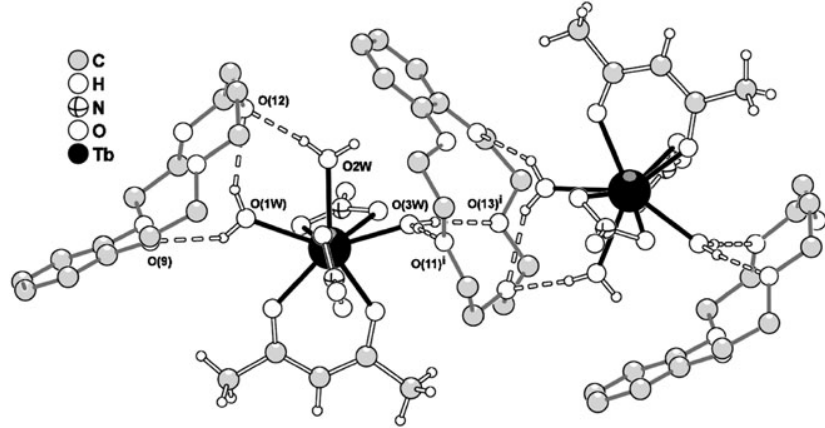

Fig. 4 Zigzag one-dimensional supramolecular tape present in $\left[\mathrm{Tb}\left(\mathrm{H}_{2} \mathrm{O}\right)_{3}\left(\mathrm{NO}_{3}\right)_{2}(\mathrm{acac})\right] \cdot \mathrm{C}_{14} \mathrm{H}_{20} \mathrm{O}_{5}$, assembled by strong $\mathrm{O}-\mathrm{H} \cdots \mathrm{O}$ hydrogen bonds. H-atoms associated with the benzo-15-crown-5 molecules have been omitted for clarity. Symmetry codes used to generate equivalent atoms: (i) $-x,-1 / 2+y, 1 / 2-z$. For hydrogen-bonding details see Table 3 .

observed for the compound $\left[\mathrm{Tb}\left(\mathrm{H}_{2} \mathrm{O}\right)_{3}\left(\mathrm{NO}_{3}\right)_{2}\right.$ (acac)]. $\mathrm{C}_{14} \mathrm{H}_{20} \mathrm{O}_{5}$ 5. Apart from an increase in the relative intensity of the observed shoulder centered around $316 \mathrm{~nm}$, this large broad band presents approximately the same structured profile as that observed in the PLE spectrum of the Tb-based compound $\mathbf{5}$.

The PL features of the Eu-based [60]fullerene derivative compound 3 were investigated between RT and $12 \mathrm{~K}$ (Fig. 7). The spectra are mainly constituted by the typical $\mathrm{Eu}^{3+}$-red emission originated from transitions occurring between the first excited state ${ }^{5} \mathrm{D}_{0}$ and the ground multiplet ${ }^{7} \mathrm{~F}_{0-4}$. A maximum splitting of the intra- $4 \mathrm{f}^{6}$ transitions, particularly evident for the ${ }^{5} \mathrm{D}_{0} \rightarrow{ }^{7} \mathrm{~F}_{1,2}$ (3 and 5 Stark components, respectively), suggests a low-site symmetry group around the metal ions. The low-temperature spectrum presents a more structured profile, namely for the ${ }^{5} \mathrm{D}_{0} \rightarrow{ }^{7} \mathrm{~F}_{1,2,4}$ transitions, and it was observed an increase around $90 \%$ of the PL intensity. However, no significant changes were detected in the energy, fwhm or the number of Stark components, strongly indicating that the local environment of $\mathrm{Eu}^{3+}$ consists of a continuous distribution of relatively similar low symmetry network sites. Moreover, the cation lines remain unchanged as the excitation wavelength is varied between 275 and $465 \mathrm{~nm}$.

The RT lifetime of the ${ }^{5} \mathrm{D}_{0}$ level was monitored within the ${ }^{7} F_{2}$ multiplet (excitation wavelength of $275 \mathrm{~nm}$ ). In a similar way to that observed for the $\mathrm{Tb}^{3+}$-based compound $\mathbf{5}$ the data can be fitted by a single exponential function (not shown), thus

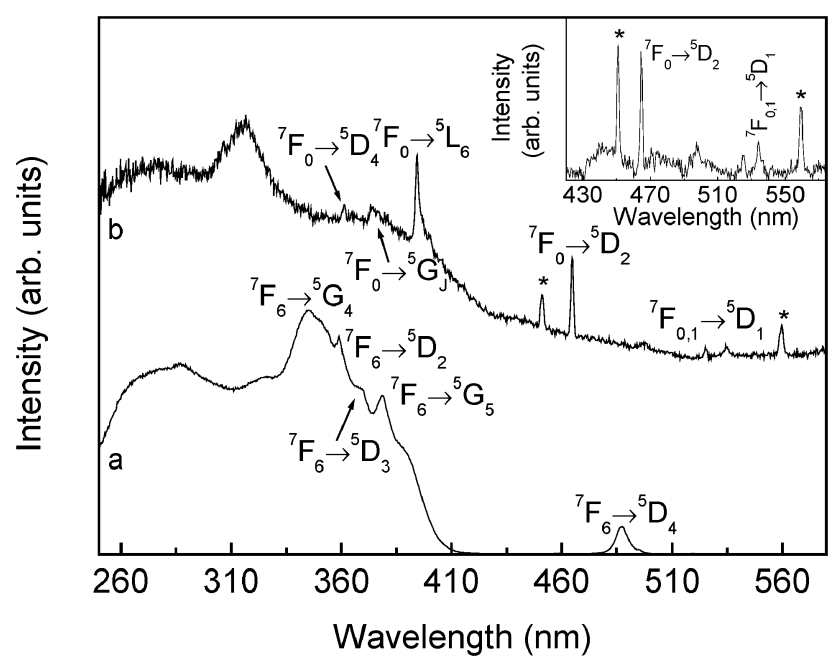

Fig. 5 RT PLE spectra of compound 5 (a) and of 3 (b), monitored around 544.0 and $614.6 \mathrm{~nm}$, respectively. The inset shows the low-temperature $(12 \mathrm{~K})$ spectrum of compound 3 monitored around $614.6 \mathrm{~nm}$. (* vibronic Stokes-lines). 


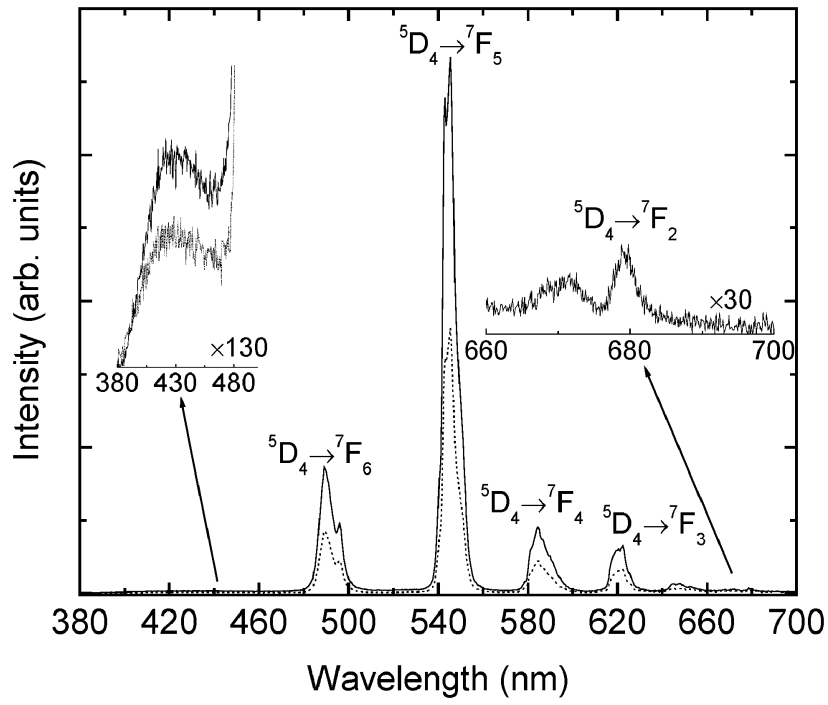

Fig. 6 RT PL spectra of compound 5 excited at 287 (dotted line) and $345 \mathrm{~nm}$ (solid line).

indicating a great homogeneity of the $\mathrm{Eu}^{3+}$ local environment. The corresponding lifetime is $\tau=0.233 \pm 0.007 \mathrm{~ms}$.

A hypothetical $\mathrm{Eu}^{3+}$ first coordination shell for the [60]fullerene derivative compound 3 could be derived using the energy shift of the ${ }^{5} \mathrm{D}_{0} \rightarrow{ }^{7} \mathrm{~F}_{0}$ transition with respect to the energy calculated for gaseous $\mathrm{Eu}^{3+}$, and the structural data proposed by XRD results for compound $\mathbf{5}$. The energy of the ${ }^{5} \mathrm{D}_{0} \rightarrow{ }^{7} \mathrm{~F}_{0}$ transition is related with the so-called nephelauxetic effect, in which the red shift observed for $\mathrm{d}-\mathrm{d}$ and $\mathrm{f}-\mathrm{f}$ energy differences, with respect to the free ion, is related to a decrease in the values of the Slater integrals and spin-orbit coupling parameter. ${ }^{38-40}$ A phenomenological equation, expressing the nephelauxetic effect in terms of the red shift observed for the ${ }^{5} \mathrm{D}_{0} \rightarrow{ }^{7} \mathrm{~F}_{0}$ transition in a large series of $\mathrm{Eu}^{3+}$ compounds, with respect to the energy calculated for gaseous $\mathrm{Eu}^{3+}\left(17373 \mathrm{~cm}^{-1}\right)$, has been proposed as ${ }^{41}$

$$
\begin{aligned}
\Delta E \equiv E\left({ }^{5} \mathrm{D}_{0} \rightarrow{ }^{7} \mathrm{~F}_{0}\right)_{\text {complex }}-E\left({ }^{5} \mathrm{D}_{0} \rightarrow{ }^{7} \mathrm{~F}_{0}\right)_{\text {gaseous }} \\
=\mathrm{C}_{\mathrm{N}}\left(n_{1} \delta_{1}+\cdots+n_{j} \delta_{j}\right)
\end{aligned}
$$

in which $\mathrm{C}_{\mathrm{N}}$ is an adjustable coefficient associated with the total number of $\mathrm{Eu}^{3+}$ first-neighbours, $n_{j}$ is the number of type

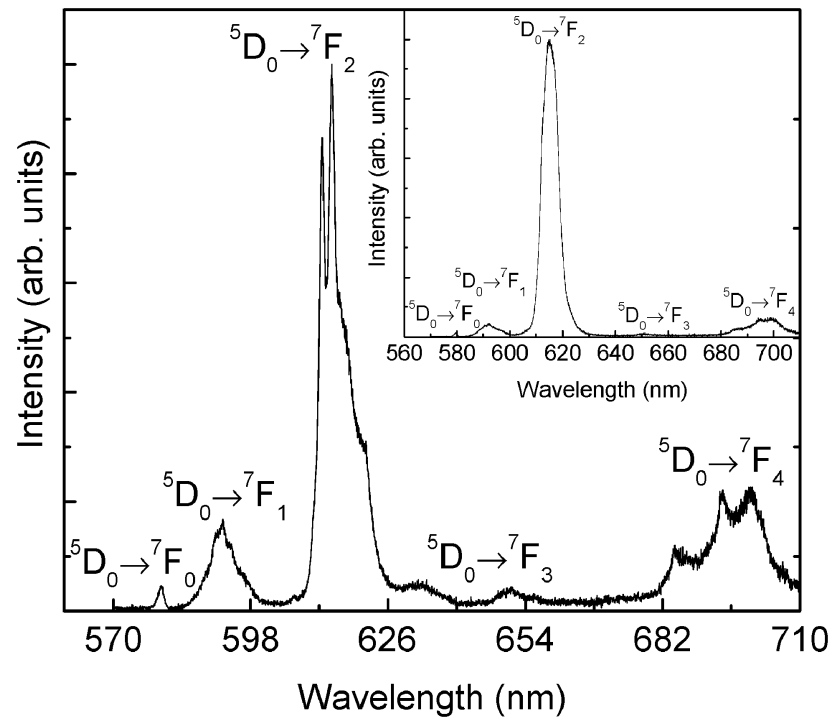

Fig. 7 Low-temperature (12 K) PL spectrum of Eu-based [60]fullerene derivative compound 3 excited at $316 \mathrm{~nm}$. The inset shows the PL spectrum for the same compound obtained at RT under the same excitation wavelength. $j$ atoms in the first coordination shell and $\delta_{j}$ is an adjusted parameter which measures the tendency of a particular atom to bond covalently to the $\mathrm{Eu}^{3+}$ cation. ${ }^{41}$ Attending to the X-ray crystal structure derived for compound $\mathbf{5}$ and in order to verify if the isolated compound can act as a model for the coordination shell of the lanthanide [60]fullerene derivatives, we assumed that the $\mathrm{Eu}^{3+}$ first neighbours are the same as those surrounding the $\mathrm{Tb}^{3+}$ cations in compound $\mathbf{5}$. Such an assumption was also further supported by vibrational and NMR data. In light of the single-crystal structure of compound 5, a possible coordination shell for $\mathrm{Eu}^{3+}$ may be formed by two charged carboxylate oxygen atoms, OT, four nitrate oxygen atoms, $\mathrm{ON}$, and three water molecules, OW. We found a theoretical ${ }^{5} \mathrm{D}_{0} \rightarrow{ }^{7} \mathrm{~F}_{0}$ energy shift of $-118.8 \pm 3 \mathrm{~cm}^{-1}$, which compares well with the experimental value, $-121.9 \pm 0.7 \mathrm{~cm}^{-1}$, strongly suggesting that no significant changes were induced in the metal ion local site when the $\mathrm{C}_{60}$ moieties are present.

Decay time measurements and purely radiative ${ }^{5} \mathrm{D}_{0} \rightarrow{ }^{7} \mathrm{~F}_{0-4}$ transition probabilities can be used additionally to support that the number of $\mathrm{Eu}^{3+}$-coordinated water molecules in the [60]fullerene derivative compound is the same as that found by XRD measurements for the $\mathrm{Tb}^{3+}$-based compound $\mathbf{5}$. The Horrocks' approach ${ }^{42-44}$ considers the utilization of decay time measurements in $\mathrm{H}_{2} \mathrm{O}$ and $\mathrm{D}_{2} \mathrm{O}$ through the empirical formula: ${ }^{42,43}$

$$
q=1.05\left[\frac{1}{\tau\left(\mathrm{H}_{2} \mathrm{O}\right)}-\frac{1}{\tau\left(\mathrm{D}_{2} \mathrm{O}\right)}\right]
$$

where $q$ is the number of water molecules, $\tau\left(\mathrm{H}_{2} \mathrm{O}\right)$ is the decay time (ms) in water and $\tau\left(\mathrm{D}_{2} \mathrm{O}\right)$ is the decay time in $\mathrm{D}_{2} \mathrm{O}$. Recently a correction of the above formula was proposed by the same group ${ }^{44}$

$$
q=1.11\left[\frac{1}{\tau\left(\mathrm{H}_{2} \mathrm{O}\right)}-\frac{1}{\tau\left(\mathrm{D}_{2} \mathrm{O}\right)}-0.31\right]
$$

However, a currently found drawback for those working with $\mathrm{Eu}^{3+}$ as a structural probe lies in obtaining decay time values in $\mathrm{D}_{2} \mathrm{O}$. Most laboratories do not have $\mathrm{D}_{2} \mathrm{O}$ easily available, it is expensive and hygroscopic in the sense that fast exchange $\mathrm{D}_{2} \mathrm{O}-\mathrm{H}_{2} \mathrm{O}$ occurs with atmospheric water. This problem can be overcome supposing that the decay time observed in $\mathrm{D}_{2} \mathrm{O}$ can be considered as a contribution of purely radiative process. $\mathrm{Eu}^{3+}$ fortunately possesses a purely magnetic dipolar transition $\left({ }^{5} \mathrm{D}_{0} \rightarrow{ }^{7} \mathrm{~F}_{1}\right)$, which does not depend on the ligand field and therefore its intensity may be considered as a reference. ${ }^{45}$ Einstein's spontaneous emission coefficient for that transition $\left(A_{01}\right)$ is readily determined from the coefficient calculated in vacuum $\left(\mathrm{A}^{\prime}{ }_{01}=14.65 \mathrm{~s}^{-1}\right)^{46}$ and the refractive index $n\left(\mathrm{~A}_{01}=\right.$ $\left.\mathrm{A}^{\prime}{ }_{01} \cdot n^{3}\right)$. An average index of refraction equal to 1.5 was considered leading to $\mathrm{A}\left({ }^{5} \mathrm{D}_{0} \rightarrow{ }^{7} \mathrm{~F}_{1}\right) \approx 50 \mathrm{~s}^{-1} .{ }^{47}$ In this way, considering the ${ }^{5} \mathrm{D}_{0} \rightarrow{ }^{7} \mathrm{~F}_{0-4}$ transitions in the PL spectrum (the ${ }^{5} \mathrm{D}_{0} \rightarrow{ }^{7} \mathrm{~F}_{5,6}$ contributions were too small and therefore neglected) the total radiative coefficient $\left(\tau_{\mathrm{RAD}}{ }^{-1}\right)$ is obtained from the experimental intensities, $\tau_{\mathrm{RAD}}{ }^{-1}=1.395 \mathrm{~ms}^{-1}$. Substituting $\tau_{\mathrm{RAD}}{ }^{-1}$ for $\tau^{-1}\left(\mathrm{D}_{2} \mathrm{O}\right)$ in Horrocks' formula (eqn. (3)) one obtains $2.9 \pm 0.1$ water molecules for $\mathrm{Eu}^{3+}$ in [60]fullerene derivative compound $\mathbf{3}$, which is exactly the number derived from XRD data for the $\mathrm{Tb}^{3+}$ compound $\mathbf{5}$.

\section{Experimental}

\section{Syntheses}

All chemicals were of at least reagent grade and were used as supplied by Aldrich. [60]Fullerene "gold grade" (>99.4\%) was supplied by Aventis R\&T and was used without further purification. 
Benzo-15-crown-5 [60]fulleropyrrolidine (1). A mixture of [60]fullerene $(120 \mathrm{mg} ; 0.17 \mathrm{mmol}), N$-methylglycine $(20.1 \mathrm{mg}$; $0.22 \mathrm{mmol}$ ) and 4-formylbenzo-15-crown-5 (33 mg; $0.11 \mathrm{mmol}$ ) was refluxed in toluene $(45 \mathrm{ml})$ under nitrogen atmosphere for $5 \mathrm{~h}$. After cooling to room temperature, the brown mixture was purified using column chromatography (silica gel) set up with a gradient of toluene to toluene/ethyl acetate/methanol $(2: 2$ : 1) as eluent. Adduct 1, a brown solid, was dried under vacuum (19.5 mg; $17 \%$ yield) and characterised by spectroscopic methods. ${ }^{1} \mathrm{H}$ NMR $\left(500 \mathrm{MHz} ; \mathrm{CDCl}_{3}\right) \delta=2.80(\mathrm{~s}, 3 \mathrm{H}$, $\mathrm{NCH}_{3}$ ), 3.74-3.76 (m, 8H, crown), 3.88-3.91 (m, 4H, crown), 4.13-4.14 (m, 4H, crown), 4.24 (d, $\left.J=9.4 \mathrm{~Hz}, 1 \mathrm{H}, \mathrm{NCH}_{2}\right), 4.85$ (s, 1H, NCH-Ar), 4.97 (d, $J=9.4 \mathrm{~Hz}, 1 \mathrm{H}, \mathrm{NCH}_{2}$ ), 6.88 (br m, $3 \mathrm{H}, \mathrm{Ar}-\mathrm{H}) ;{ }^{13} \mathrm{C}$ NMR $\left(126 \mathrm{MHz} ; \mathrm{CDCl}_{3}\right) \delta=40.1\left(\mathrm{NCH}_{3}\right)$, $68.5,68.8,68.9,69.2,69.4,69.9,70.3,70.6,70.9\left(\mathrm{C}_{\mathrm{sp}^{3}}-\mathrm{C}_{60}\right.$, $\mathrm{NCH}_{2}$ and $\left.\mathrm{C}_{\text {crown }}\right), 83.3(\mathrm{NCH}), 113.1(\mathrm{Ar}-\mathrm{CH}), 122.5(\mathrm{Ar}-$ $\left.\mathrm{C}_{\mathrm{q}}\right), 129.8(\mathrm{Ar}-\mathrm{CH}) 135.7,135.8,136.45,136.49,139.7,139.8$, 140.1, 140.2, 141.7, 142.01, 142.04, 142.1, 142.15, 142.21, 142.5, $142.56,142.58,144.4,144.7,145.2,145.28,145.33,145.47$, $145.52,145.8,145.95,146.08,146.14,146.18,146.20,146.24$, $146.3,146.5,146.8,147.28,147.30,148.2,148.9,149.0,153.5$, 153.8, 154.1, $156.2\left(\mathrm{C}_{\mathrm{q}}-\mathrm{C}_{60}\right.$ and $\left.\mathrm{Ar}-\mathrm{C}_{\mathrm{q}}\right) ;{ }^{13} \mathrm{C} \mathrm{CP}$ MAS NMR $(101 \mathrm{MHz}) \delta=40.2\left(\mathrm{NCH}_{3}\right), 69.4\left(\mathrm{C}_{\mathrm{sp}^{3}}-\mathrm{C}_{60}, \mathrm{NCH}_{2}\right.$ and

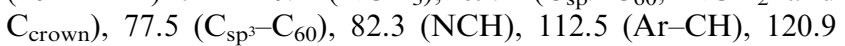
$\left(\mathrm{Ar}-\mathrm{C}_{\mathrm{q}}\right), 129.2(\mathrm{Ar}-\mathrm{CH}), 142.1,145.9\left(\mathrm{C}_{\mathrm{q}}-\mathrm{C}_{60}\right.$ and $\left.\mathrm{Ar}-\mathrm{C}_{\mathrm{q}}\right)$; MS (MALDI-TOF) $[\mathrm{M}]^{+}=1044,\left[\mathrm{C}_{60}\right]=720$.

Lanthanide (Ln) compounds of benzo-15-crown-5 [60|fulleropyrrolidine (2-4). To a solution of compound 1 in $\mathrm{CHCl}_{3}$ was added a suspension of $\mathrm{Ln}(\mathrm{acac})_{3} \cdot n \mathrm{H}_{2} \mathrm{O}$ in $\mathrm{CHCl}_{3}$, followed by a solution of $\mathrm{Ln}\left(\mathrm{NO}_{3}\right)_{3} \cdot n \mathrm{H}_{2} \mathrm{O}$ in acetone : $\mathrm{CHCl}_{3}(1 \mathrm{ml}: 1$ $\mathrm{ml}$ ). The resulting mixture was stirred for $1 \mathrm{~h}$ at room temperature leading to the formation of a brown solid, which was centrifuged, washed with $\mathrm{CHCl}_{3}(2 \times 1.5 \mathrm{ml})$ and acetone $(2 \times 1.5 \mathrm{ml})$ and then dried under vacuum. $\mathbf{L n}=\mathbf{L a}(2): 44.6$ $\mathrm{mg}$ compound $1(0.043 \mathrm{mmol})$ in $5 \mathrm{ml} \mathrm{CHCl}_{3} ; 18.7 \mathrm{mg}$ $\mathrm{La}(\text { acac })_{3} \cdot n \mathrm{H}_{2} \mathrm{O}(0.043 \mathrm{mmol})$ in $3 \mathrm{ml} \mathrm{CHCl}{ }_{3} ; 14 \mathrm{mg} \mathrm{La}\left(\mathrm{NO}_{3}\right)_{3}$ . $n \mathrm{H}_{2} \mathrm{O}$ (0.043 mmol); compound 2 (14.9 mg; $24 \%$ yield $),{ }^{13} \mathrm{C}$ CP MAS NMR (101 MHz) $\delta=23.9\left(\mathrm{CH}_{3}-\mathrm{acac}\right), 70.5\left(\mathrm{C}_{\mathrm{sp}^{3}}-\right.$ $\mathrm{C}_{60}, \mathrm{NCH}_{2}$ and $\left.\mathrm{C}_{\text {crown }}\right), 84.3(\mathrm{NCH}), 93.5$ (CH-acac), 146.4 $\left(\mathrm{C}_{\mathrm{q}}-\mathrm{C}_{60}\right.$ and $\left.\mathrm{Ar}-\mathrm{C}_{\mathrm{q}}\right), 166.1$ and $181.7(\mathrm{CO}-\mathrm{acac}) . \mathbf{L n}=\mathbf{E u}(3)$ : $20.9 \mathrm{mg}$ compound $1(0.020 \mathrm{mmol})$ in $2 \mathrm{ml} \mathrm{CHCl}$; $9.8 \mathrm{mg}$ $\mathrm{Eu}(\mathrm{acac})_{3} \cdot n \mathrm{H}_{2} \mathrm{O}(0.020 \mathrm{mmol})$ in $4 \mathrm{ml} \mathrm{CHCl}{ }_{3} ; 18.7 \mathrm{mg}$ $\mathrm{Eu}\left(\mathrm{NO}_{3}\right)_{3} \cdot 5 \mathrm{H}_{2} \mathrm{O}(0.044 \mathrm{mmol})$; compound $3(6.9 \mathrm{mg} ; 24 \%$ yield). $\mathbf{L n}=\mathbf{T b}(\mathbf{4}): 21.1 \mathrm{mg}$ compound $\mathbf{1}(0.020 \mathrm{mmol})$ in $2 \mathrm{ml}$ $\mathrm{CHCl}_{3} ; 10 \mathrm{mg} \mathrm{Tb}(\mathrm{acac})_{3} \cdot n \mathrm{H}_{2} \mathrm{O}(0.022 \mathrm{mmol})$ in $4 \mathrm{ml} \mathrm{CHCl} 3$; $19.0 \mathrm{mg} \mathrm{Tb}\left(\mathrm{NO}_{3}\right)_{3} \cdot 5 \mathrm{H}_{2} \mathrm{O}(0.044 \mathrm{mmol})$; compound $4(6.9 \mathrm{mg}$; $23 \%$ yield).

$\left[\mathrm{Tb}\left(\mathrm{H}_{2} \mathrm{O}\right)_{3}\left(\mathrm{NO}_{3}\right)_{2}(\mathbf{a c a c})\right] \cdot \mathbf{C}_{\mathbf{1 4}} \mathrm{H}_{20} \mathrm{O}_{\mathbf{5}}$ (5). To a solution in acetone $(1 \mathrm{ml})$ of benzo-15-crown-5 $(67 \mathrm{mg} ; 0.25 \mathrm{mmol})$, was added a solution of $\mathrm{Tb}(\mathrm{acac})_{3} \cdot n \mathrm{H}_{2} \mathrm{O}(114 \mathrm{mg} ; 0.25 \mathrm{mmol})$ in a mixture of acetone : $\mathrm{CHCl}_{3}(1 \mathrm{ml}: 3 \mathrm{ml})$, followed by the addition of $\mathrm{Tb}\left(\mathrm{NO}_{3}\right)_{3} \cdot 5 \mathrm{H}_{2} \mathrm{O}(109 \mathrm{mg} ; 0.25 \mathrm{mmol})$ dissolved in acetone $(1 \mathrm{ml})$. The resulting solution was stirred at room temperature for $2.5 \mathrm{~h}$, leading to a precipitate which was centrifuged and the filtrate left to stand overnight in the refrigerator giving colourless crystals of 5 (65 mg, 36\% yield). Anal. Calcd. for $\mathrm{C}_{19} \mathrm{H}_{33} \mathrm{~N}_{2} \mathrm{O}_{17} \mathrm{~Tb}$ (in \%): C, 31.67; N, 3.89; $\mathrm{H}$, 4.58. Found: C, 31.55; N, 3.83; H, 4.50.

\section{Crystallography}

A suitable single-crystal of $\left[\mathrm{Tb}\left(\mathrm{H}_{2} \mathrm{O}\right)_{3}\left(\mathrm{NO}_{3}\right)_{2}(\mathrm{acac})\right] \cdot \mathrm{C}_{14} \mathrm{H}_{20} \mathrm{O}_{5}$ was mounted on a glass fibre using perfluoropolyether oil. ${ }^{48}$ Data were collected at 180(2) K on a Nonius Kappa charge coupled device (CCD) area-detector diffractrometer (Mo $\mathrm{K}_{\alpha}$ graphite-monochromated radiation, $\lambda=0.7107 \AA$ ), equipped with an Oxford Cryosystems cryostream and controlled by the
Collect software package. ${ }^{49}$ Images were processed using the software packages of Denzo and Scalepack, ${ }^{50}$ and the data were corrected for absorption by using the empirical method employed in Sortav. ${ }^{51,52}$ The structure was solved by the direct methods of SHELXS-97, ${ }^{53}$ and refined by full-matrix least squares on $F^{2}$ using SHELXL-97. ${ }^{54}$ Non-hydrogen atoms were generally directly located from difference Fourier maps and refined, when possible, with anisotropic displacement parameters. The last difference Fourier map synthesis showed the highest peak $\left(1.117 \mathrm{e}^{-3}\right)$ located at $1.52 \AA$ from $\mathrm{H}(1 \mathrm{~A})$, and the deepest hole $\left(-0.756 \mathrm{e}^{-3}\right)$ located at $0.89 \AA$ from $\mathrm{Tb}(1)$.

Hydrogen atoms bound to carbon were placed in calculated positions and refined using a riding model with an isotropic displacement parameter fixed at $x$ times $U_{\text {eq }}$ for the atom to which they are attached $\left(x=1.5\right.$ for $-\mathrm{CH}_{3}$ groups, and $x=1.2$ for the remaining hydrogen atoms). $\mathrm{H}(3 \mathrm{C})$ from $\mathrm{acac}^{-}$[bound to $\mathrm{C}(3)$ ] was also directly located and refined freely with an independent isotropic displacement parameter. Hydrogen atoms from coordinated water molecules were directly located from successive difference Fourier maps, and refined with the $\mathrm{O}-\mathrm{H}$ and $\mathrm{H} \cdots \mathrm{H}$ distances restrained to $0.85(1) \AA$ and $1.39(1)$ $\AA$, respectively (in order to ensure a chemically reasonable geometry for these molecules), and using a riding model with an isotropic displacement parameter fixed at 1.5 times $U_{\text {eq }}$ of the atom to which they are attached.

Information concerning crystallographic data collection and structure refinement details are given as footnotes and as Supporting Information (CIF file) $\ddagger$ Bond lengths and angles for the $\left[\mathrm{Tb}\left(\mathrm{H}_{2} \mathrm{O}\right)_{3}\left(\mathrm{NO}_{3}\right)_{2}\right.$ (acac)] complex are given in Table 2 . Hydrogen bonding geometry is described in Table 3.

Crystallographic data (excluding structure factors) for the structure of $\left[\mathrm{Tb}\left(\mathrm{H}_{2} \mathrm{O}\right)_{3}\left(\mathrm{NO}_{3}\right)_{2}(\mathrm{acac})\right] \cdot \mathrm{C}_{14} \mathrm{H}_{20} \mathrm{O}_{5}$ have been deposited with the Cambridge Crystallographic Data Centreł.

\section{Instrumentation}

Infrared spectra were measured from $\mathrm{KBr}$ pellets on a Mattson 7000 FT instrument. Raman spectra were recorded using a Bruker RFS100/S FTspectrometer (Nd:YAG laser, $1064 \mathrm{~nm}$ excitation). ${ }^{1} \mathrm{H}$ and ${ }^{13} \mathrm{C}$ NMR spectra were obtained using a Brüker AVANCE 500 spectrometer $\left({ }^{1} \mathrm{H}, 500.13 \mathrm{MHz} ;{ }^{13} \mathrm{C}\right.$, $125.758 \mathrm{MHz})$ referenced to $\mathrm{Si}\left(\mathrm{CH}_{3}\right)_{4}$ or the solvent. ${ }^{13} \mathrm{C} \mathrm{CP}$ MAS solid-state NMR spectra were measured at $100.62 \mathrm{MHz}$ on a $9.4 \mathrm{~T}$ wide-bore Bruker Avance 400 spectrometer. The spectra were acquired with a $4 \mu \mathrm{s} 90^{\circ}$ proton pulse, $2 \mathrm{~ms}$ contact time spinning rate of $7 \mathrm{kHz}$ and $5 \mathrm{~s}$ recycle delays. Chemical shifts are quoted in ppm relative to TMS. Elemental analyses for carbon, nitrogen and hydrogen were performed in a FISONS EA1108 instrument. Mass spectrum of compound 1 was recorded on a Bruker Autoflex Maldi instrument using a HCCA ( $\alpha$-cyano-4-hydroxycinnamic acid) matrix. Energy-dispersive X-ray emission analysis (EDX) was performed on a FEG-SEM Hitachi S4100 microscope operating at $25 \mathrm{kV}$. The samples were prepared by deposition of an aliquot of an acetone suspension of the sample on aluminium pieces and then coated with evaporated carbon. Column chromatography was carried out using silica gel (Merk 0.063-0.200 mm).

The emission, PL, and excitation, PLE, spectra and lifetime measurements were detected between $12 \mathrm{~K}$ and room-temperature on a modular double grating excitation spectrofluorimeter with a TRIAX 320 emission monochromator (Fluorolog-3, Jobin Yvon-Spex) coupled to a R928 Hamamatsu photomultiplier, in the front face acquisition mode. All the photoluminescence spectra were corrected for optics and detection spectral response.

\section{Acknowledgements}

We wish to thank the Fundação para a Ciência e a Tecnologia (FCT, Portugal) for the general financial POCTI programme 
(grant contract POCTI/35378/QUI/2000) supported by FEDER and the PhD scholarship No. SFRH/BD/3024/2000 (to F.A.A.P). P. Soares-Santos thanks the University of Aveiro for a $\mathrm{PhD}$ research grant.

\section{References}

1 A. L. Balch and M. M. Olmstead, Chem. Rev., 1998, 2123.

2 S. Nagase, K. Kobayashi and T. Akasaka, Bull. Chem. Soc. Jpn., 1996, 69, 2131

3 L. Garlaschelli, I. Messina, D. Pasini and P. P. Righetti, Eur. J. Org. Chem., 2002, 3385.

4 P. C. R. Soares-Santos, H. I. S. Nogueira, V. Félix, M. G. B Drew, R. A. Sá Ferreira, L. D. Carlos and T. Trindade, Chem. Mater., 2003, 15, 100.

5 P. C. R. Soares-Santos, H. I. S. Nogueira, J. Rocha, V. Félix, M. G. B. Drew, R. A. Sá Ferreira, L. D. Carlos and T. Trindade Polyhedron, 2003, 22, 3529.

6 P. C. R. Soares-Santos, H. I. S. Nogueira, V. Félix, M. G. B. Drew, R. A. Sá Ferreira, L. D. Carlos and T. Trindade, Inorg. Chem. Commun., 2003, 6, 1234.

7 P. C. R. Soares-Santos, H. I. S. Nogueira, F. A. Almeida Paz, R. A. Sá Ferreira, L. D. Carlos, J. Klinowski and T. Trindade, Eur. J. Inorg. Chem., 2003, 3609.

8 D. M. Guldi, Chem. Soc. Rev., 2002, 31, 22.

9 H. Imahori and Y. Sakata, Adv. Mater., 1997, 9, 537.

10 N. Martín, L. Sánchez, B. Illescas and I. Pérez, Chem. Rev., 1998, 2527.

11 P. C. R. Soares-Santos, T. Trindade, A. C. Tomé, R. A. Sá Ferreira, L. D. Carlos and H. I. S. Nogueira, 35th International Conference on Coordination Chemistry, Heidelberg, Germany, 2002, p. 933.

12 M. Maggini, G. Scorrano and M. Prato, J. Am. Chem. Soc., 1993, 115, 9798 .

13 Z. Guo, Y. Li, J. Xu, Z. Mao, Y. Wu and D. Zhu, Synth. Commun., 1998, 28, 1957.

14 J.-C. G. Bünzli and D. Wessner, Coord. Chem. Rev., 1984, 60, 191.

15 M. Wang, L. Jin and J.-C. G. Bünzli, Polyhedron, 1999, 18, 1853.

16 S. W. Magennis, J. Craig, A. Gardner, F. Fucassi, P. J. Cragg, N. Robertson, S. Parsons and Z. Pikramenou, Polyhedron, 2003, 22, 745.

17 Y. Liu, B.-H. Han and Y.-T. Chen, Coord. Chem. Rev., 2000 200-202, 53.

18 D. Wessner and J.-C. G. Bünzli, Inorg. Synth., 1985, 23, 155

19 J.-C. G. Bünzli, B. Klein, G. Chapuis and K. J. Schenk, Inorg. Chem., 1982, 21, 808 .

20 T. J. Lee, Hrong-Roang Sheu, T. I. Chiu and C. T. Chang, Acta Cryst., 1983, C39, 1357.

21 J. Yu, Z. Xu and G. Xu, Spectrochim. Acta, Part A, 1996, 52, 1499.

22 R. B. King and P. Heckley, J. Am. Chem. Soc., 1974, 96, 3118.

23 T. I. Razvina, V. S. Khomenko, V. V. Kuznetsova and R. A Puko, J. Appl. Spectrosc., 1973, 18/19, 1461.

24 R. M. Williams, J. M. Zwier and J. W. Verhoeven, J. Am. Chem. Soc., 1995, 117, 4093.
25 M. D. L. de la Torre, A. G. P. Rodrigues, A. C. Tomé, A. M. S Silva and J. Cavaleiro, Tetrahedron, 2004, 60, 3581

26 Y. Fukuda, A. Nakao and K. Hayashi, J. Chem. Soc., Dalton Trans., 2002, 527.

27 R. Y. Wang, D. T. Song and S. M. Wang, Chem. Commun., 2002, 368.

28 U. K. Urs, K. Shalini, T. S. Cameron, S. A. Shivashankar and T. N. G. Row, Acta Cryst., Sect. E: Structure Reports Online, 2001, 57, m457.

29 M. A. J. Moss, C. J. Jones and A. J. Edwards, J. Chem. Soc., Dalton Trans., 1989, 7, 1393.

30 P. C. Junk and M. K. Smith, Polyhedron, 2003, 22, 331.

31 O. Poncelet and L. G. Hubertpfalzgraf, Polyhedron, 1989, 8 2183.

32 R. G. Lawrence, T. A. Hamor, C. J. Jones, K. Paxton and N. M. Rowley, J. Chem. Soc., Dalton Trans., 2001, 2121.

33 P. C. Christidis, I. A. Tossidis, D. G. Paschalidis and L. C. Tzavellas, Acta Cryst., Sect. C: Cryst. Struct. Commun., 1998, 54, 1233.

34 B. Barja, R. Baggio, M. T. Garland, P. F. Aramendia, O. Pena and M. Perec, Inorg. Chim. Acta, 2003, 346, 187.

35 J. L. Atwood, L. J. Barbour, S. Dalgarno, C. L. Raston and H. R. Webb, J. Chem. Soc., Dalton Trans., 2002, 4351.

36 D. Min and S. W. Lee, Inorg. Chem. Commun., 2002, 5, 978.

37 B. D. Alleyne, A. R. Williams, L. A. Hall, A. J. P. White and D. J. Williams, Inorg. Chem., 2001, 40, 1045.

38 C. K. Jørgensen, Progr. Inorg. Chem., 1962, 4, 73.

39 L. D. Carlos and A. L. L. Videira, J. Chem. Phys., 1994, 101 8827.

40 O. L. Malta, H. J. Batista and L. D. Carlos, Chem. Phys., 2002, 282, 21.

41 S. T. Frey and W. D. Horrocks Jr., Inorg. Chim. Acta, 1995, 229, 383.

42 W. D. Horrocks Jr. and D. R. Sudnick, J. Am. Chem. Soc., 1979, 101, 334.

43 W. D. Horrocks Jr. and W. D. R. Sudnick, Acc. Chem. Res., 1981, 14, 384.

44 R. M. Supkowski and W. D. Horrocks Jr., Inorg. Chim. Acta, 2002, 340, 44.

45 L. D. Carlos, Y. Messaddeq, H. F. Brito, R. A. Sá-Ferreira, V. de Zea Bermudez and S. J. L. Ribeiro, Adv. Mater., 2000, 12, 594.

46 M. H. V. Werts, R. T. F. Jukes and J. W. Verhoeven, Phys. Chem. Chem. Phys., 2002, 4, 1542.

47 M. F. Hazenkamp and G. Blasse, Chem. Mater., 1990, 2, 105.

48 T. Kottke and D. Stalke, J. App. Cryst., 1993, 26, 615.

49 R. Hooft, Collect: Data Collection Software, Delft, The Netherlands, 1998.

50 Z. Otwinowski and W. Minor, in Methods in Enzymology, Macromolecular Crystallography, Part A, eds. C. W. Carter Jr. and R. M. Sweet, Vol. 276, Academic Press, New York, 1997, p. 307.

51 R. H. Blessing, J. Appl. Crystallogr., 1997, 30, 421.

52 R. H. Blessing, Acta Cryst. A, 1995, 51, 33.

53 G. M. Sheldrick, SHELXS-97, Program for Crystal Structure Solution, University of Göttingen, 1997.

54 G. M. Sheldrick, SHELXL-97, Program for Crystal Structure Refinement, University of Göttingen, 1997. 